\title{
EFICIENCIA ENERGÉTICA COM O EMPREGO DE LUBRIFICANTES SINTÉTICOS ESPECIAIS*
}

Resumo

O presente trabalho tem por objetivo apresentar alguns exemplos de aplicações na Indústria Siderúrgica e de Mineração (Prensa de Rolos e Torre de Resfriamento) mostrando que com o emprego de uma confiável metodologia para determinação dos benefícios energéticos é possível a implantação das medidas de conservação de energia em sistemas de força motriz instalados nestas indústrias com o simples uso de Lubrificantes Sintéticos Especiais em substituição ao largo emprego de óleos minerais. Esta solução também proporciona ganhos energéticos e financeiros expressivos e mais atrativos do que as já consagradas soluções de eficiência energética como troca de lâmpadas e /ou motores de alto rendimento. Além do mais, a troca de lubrificante já é rotina implementada nas indústrias e seus profissionais da área de manutenção, não sendo preciso treinamento adicional para implementação, tornando esta ação com o propósito de economizar energia simples e fácil de ser implementada. Este trabalho é uma parte dos resultados do projeto inovador desenvolvido pela Klüber Lubrication desde 2010, onde o principal objetivo é disponibilizar aos usuários de sua linha de produtos este recurso, internacionalmente reconhecido, de Medição \& Verificação para a comprovação de ganhos de energia em prensas de rolos com alcance de redução de cerca de $10 \%$ de consumo de energia.

Palavras-chave: Lubrificante especial; Lubrificante sintético; Eficiência energética; Prensa de rolos; Torre de resfriamento.

\section{ENERGY EFFICIENCY PROVIDED BY THE USE OF SPECIAL SYNTHETIC LUBRICANTS}

\section{Abstract}

This article aims to present some specific success cases in application for Steel and Mining Industries using a reliable methodology for determining of the energy benefits proofing that is possible the implementation of energy conservation measuring motor powered systems installed those industries with a simple change of lubricant, instead the use of actual mineral oil and provide higher attractive financial results when compares with another energy efficiency actions as switch lamps and electrical motors , in addition this procedure is a very known and often routine of maintenance professionals, become this option in a very simple and efficient solution to save energy consumption without operational updates. The work presented here shows a small part of an innovative project initiated in 2010 inside Klüber Lubrication where it was intended to transpose the challenge of proving the energy gains with the use of special synthetic lubricants made by Klüber Lubrication with achieved results around $10 \%$.

Keywords: Special lubricant; Synthetic lubricant; Energy efficiency; Roller press; Cooling tower.

1 Engenheiro Químico - Escola Politécnica USP, Mestrado em Termodinâmica- Escola Politécnica USP, Mestrado em Energias Renováveis e Eficiência Energética Escola Politécnica USP, MBA em Marketing e Gestão de Novos Negócios pela FIA-USP, Gerente de Sustentabilidade e Eficiência Energética na Klüber Lubrication Brasil, São Paulo, Brasil.

2 Klüber Lubrication, São Paulo, Brasil.

3 Engenheiro Metalurgista - Escola Politécnica USP, Gerente de Mercado na Klüber Lubrication Brasil, São Paulo, Brasil.

$4 \quad$ Klüber Lubrication, São Paulo, Brasil. 


\section{INTRODUÇÃO}

Este trabalho visa mostrar por meio de trabalhos reais feitos em equipamentos da área de Siderurgia e Mineração que há ocorrência de economia de energia com a substituição dos óleos minerais, atualmente muito utilizados na indústria na maioria das aplicações, por óleos sintéticos especiais. Comprovando a viabilidade financeira do emprego desta solução, bem como benefícios mecânicos resultantes do melhor desempenho, torna-se viável financeiramente fazer esta ação de melhoria operacional e mecânica, com o argumento adicional de eficiência energética.

Toda ação de eficiência energética somente pode ser comprovada por sólida ação de medição e verificação, apresentando dados de primeira medição do consumo de energia nos equipamentos previamente selecionados, lubrificados com óleo mineral, por um período que seja suficiente para se avaliar e aceitar como comportamento recorrente da máquina. Após este período, realiza-se a troca de todo o óleo mineral contido nos respectivos equipamentos e substitui-se pelo óleo sintético, realizandose na sequência nova medição, para que com isto faça-se a comparação.

O argumento teórico é o de que um lubrificante sintético de alta performance da Klüber Lubrication aumenta a capacidade sustentadora de cargas e a eficiência de uma máquina ou de um conjunto de engrenagens devido ao menor coeficiente de atrito entre as partes móveis.

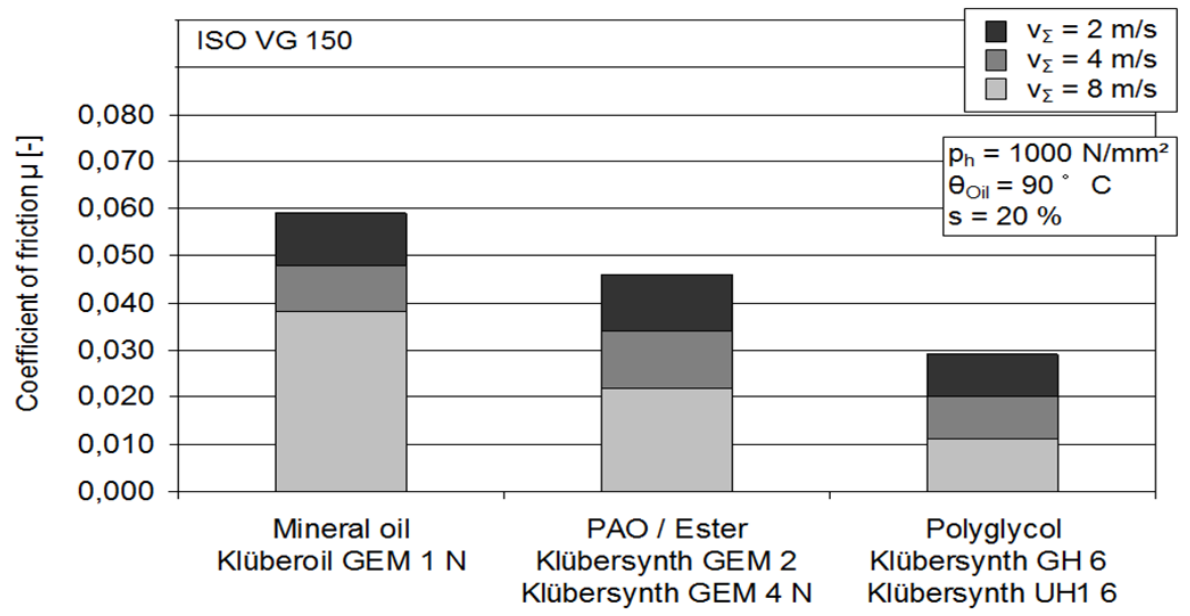

Figura 1-Coeficientes de atrito para diferentes tipos de óleo base (ISOVG 150)

Justamente devido ao menor coeficiente de atrito que chega a ser menos do que a metade daquele dos óleos minerais convencionais, o lubrificante sintético de bases PAO (polialfaolefina) e PG (poliglicol) têm a capacidade de aumentar a eficiência mecânica, o que teoricamente resulta em um menor consumo de energia.

Para a comprovação deste argumento teórico foram feitas medições, adotando o método reconhecido pelo Protocolo Internacional de Medição e Verificação (PIMVP EVO 10000 - 1:2007 BR) amplamente reconhecido pelos principais organismos nacionais e internacionais.

A maior motivação para este estudo e a sugestão da aplicação desta proposta é o fato de que segundo estudo da ANEEL, pesquisa PPH 2014, na média cerca de $60 \%$ do consumo de eletricidade da indústria são provenientes de equipamentos motrizes.

Por equipamento motriz industrial podemos considerar os compressores de ar, máquinas movimentadas por moto-redutores e bombas como os principais 
consumidores e os de uso mais difundido e usual nos maquinários de processo industrial. Em todos estes equipamentos via de regra é exigida a aplicação de lubrificantes e, com isto, seguindo o conceito de substituirmos lubrificantes base mineral nestes equipamentos podemos obter redução de consumo de pelo menos $4 \%$.

\section{MATERIAIS E MÉTODOS}

As medições para determinação das variáveis envolvidas na quantificação dos resultados foram realizadas diretamente no equipamento selecionado. Além das medições referentes à energia consumida, foi levada em consideração a produção do equipamento para determinação do consumo específico (KWh / ton).

É imprescindível considerar que existem outras variáveis com forte influência no consumo energético tais como condições de processo de produção ou intervenções elétricas e mecânicas.

Para exatidão na comparação, é necessário que todas estas variáveis e condições sejam as mesmas nos períodos baseline (medição inicial com lubrificante óleo mineral) e post retrofit (medição posterior com lubrificante sintético Klüber Lubrication). O limite de medição para determinação dos resultados é restrito ao equipamento de força motriz envolvido, através da medição contínua da energia consumida pelo mesmo, da produção do equipamento e das outras variáveis de influência.

Os equipamentos que demonstramos neste artigo, por sua importância na aplicação de lubrificantes e pelo alto consumo energético dos equipamentos em uma planta são:

\begin{tabular}{|l|l|}
\hline \multicolumn{1}{|c|}{ Equipamento } & \multicolumn{1}{c|}{ Fabricante } \\
\hline Redutor de Acionamento de Prensa de Rolos ( Roller Press) & Polysius / Siemens Flender \\
\hline Redutor de Torre de Resfriamento (Cooling Tower) & SEW -Eurodrive \\
\hline
\end{tabular}

Tabela 1-Equipamentos objeto de análise

\section{REDUTOR DE PRENSA DE ROLOS}

A prensa de rolos é um equipamento novo empregado na indústria de mineração e seu emprego tem crescido bastante nos últimos anos. Os moinhos e britadores de rolos (cada um deles tem uma potência média de 1,4 MW), que são considerados com motor elétrico de grande porte, possuem - a título de referência - consumo anual mínimo de $11.000 \mathrm{MWh}$. Considerando-se o custo médio de energia de $\mathrm{R} \$$ 170,00 / MWh, somente este equipamento acarreta uma despesa anual de pelo menos $R \$ 1.870 .000,00$. É um custo expressivo, onde qualquer ação que resulte em redução de consumo será percebida pela empresa. Atualmente, a tecnologia utilizada pela prensa de rolos amadureceu, a ponto de estar presente nos principais projetos em desenvolvimento para a indústria mineral. Esta tecnologia está também operando em plantas que processam diferentes tipos de minério, tornando-se difundida em seu processamento e sendo progressivamente aplicada a materiais considerados duros e abrasivos, especialmente na preparação do pellet feed.

O princípio de funcionamento da prensa de rolos se dá por meio da aplicação de pressão a um leito de material por um par de rolos que giram em sentido contrário. Um dos rolos é fixo e outro é móvel e se desloca sobre guias, sendo posicionado por 
sistemas hidráulicos. Cada rolo é acionado por um conjunto motor + redutor planetário, em cujos reservatórios e rolamentos é empregado o lubrificante, tendo em média 450 litros de óleo em cada reservatório.

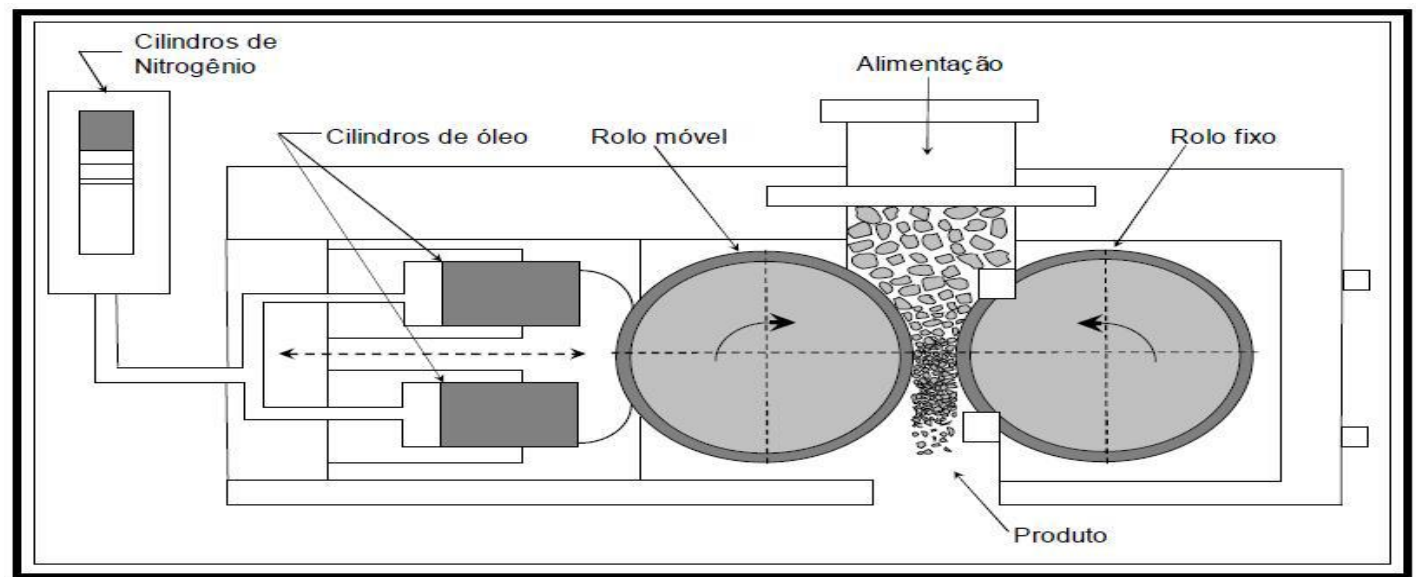

Figura 2 - Secão transversal de uma prensa de rolos : Fonte: (Wardrop Engineering Inc, 2007, s/p)

O tempo da medição de consumo de energia para a linha de base (óleo mineral) e para o pós retrofit (óleo sintético Klüber Lubrication) foi tal que compreendeu um ciclo de operação normal da unidade, englobando todos os produtos fabricados pela mesma ou pelo menos $80 \%$ de sua representatividade.

Os resultados desta medição foram determinados por meio da comparação do consumo de energia, levando em conta o mesmo comportamento de processo e produtos.

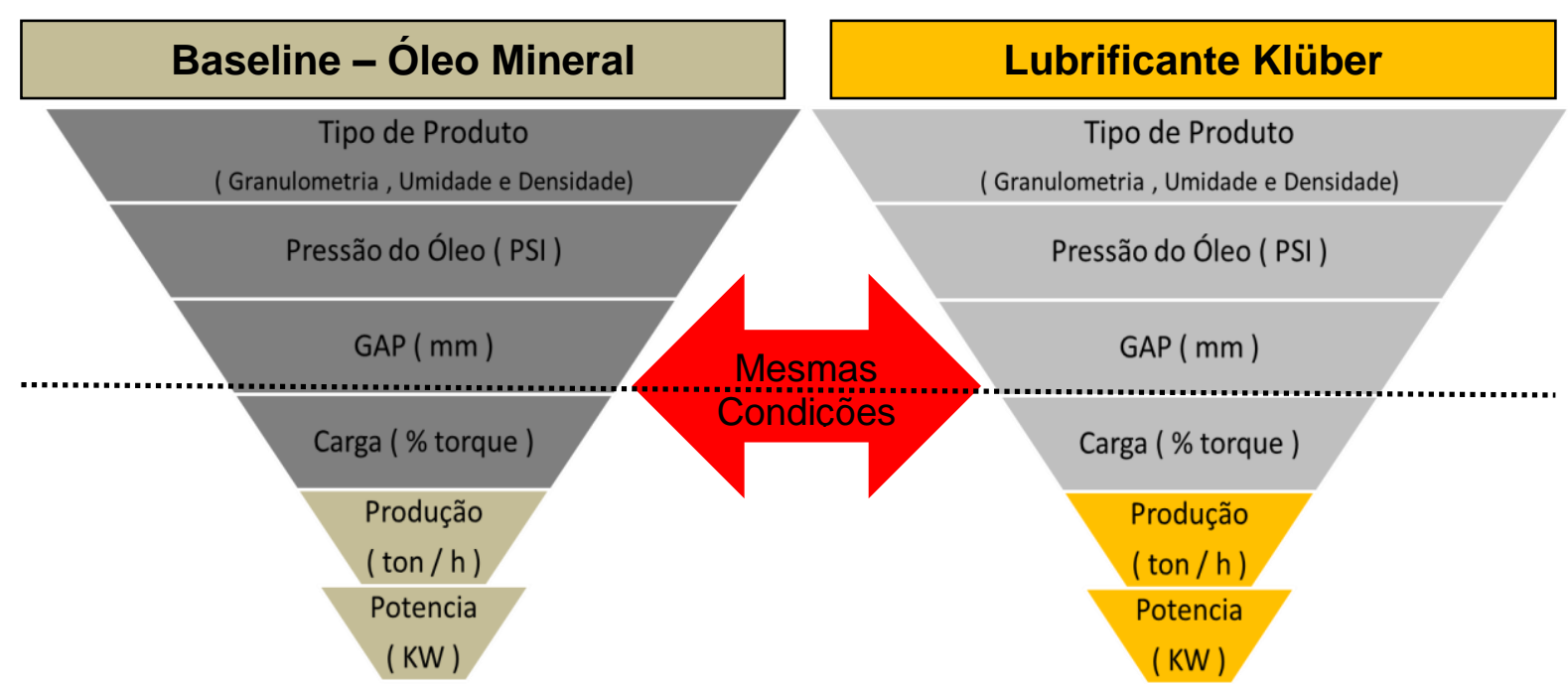

Figura 3 - Variáveis e condições de processo medidas e comparadas Mineral x Sintético

A produção e a eficiência foram avaliadas nas mesmas condições de trabalho e tanto para a linha de base quanto para o pós retrofit foram representados por uma função (modelo matemático) que descreve a economia da unidade do consumo de referência e determinado como sendo de:

$E i=f($ Potência, Produção $i$, Tempo $)$ 
Onde :

$\mathrm{E}_{\mathrm{i}}=$ Energia consumida na manufatura do produto "i” no período (baseline e pós retrofit) [KWh]

Produção i = Volume de produção do produto "i" no sistema [ toneladas ]

Tempo = duração da produção do produto "i” [ horas].

Numa prensa de rolos o trabalho útil é a pressão exercida pelo minério, que pode ser representada pela divisão do valor da vazão (ton/hora) pelo valor do GAP médio. Esta pressão tem impacto direto na Potencia Elétrica alimentada nos motores, Pot $_{\text {eletrica }}=f\left(\frac{V 2}{G A P}\right)$.

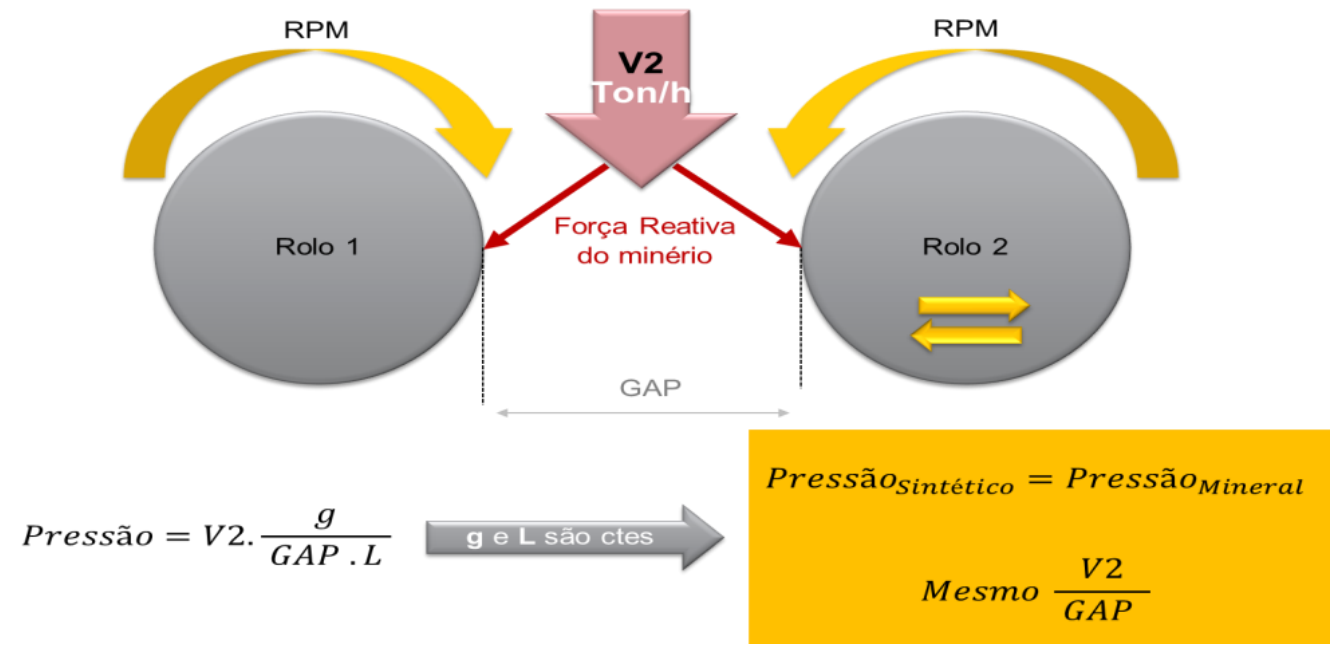

Figura 4-Componentes de força nos rolos de uma prensa de rolos

A comparação de Potência nos dois períodos foi feita na mesma condição de esforço, ou seja, no mesmo valor de $\frac{\mathrm{V} 2}{\mathrm{GAP}}$.

Este trabalho de medição e troca de lubrificantes foi feito em uma empresa mineradora localizada no Estado do Espírto Santo, Brasil.

- Período Baseline: 01/Janeiro 2015 a 15/Junho 2015.

- Troca de óleo: 17 Junho 2015.

- Período Post - Retrofit: 18 Junho a 18 Agosto 2015.

- Intervalo de medição e registro:1 minuto.

- Não houve diferenças nas características mineralógicas nos dois períodos.

\subsection{Resultados}

A primeira análise realizada foi uma comparação estatística pelo valor da mediana (percentil 50\%) com a finalidade de identificar se houve mudanças significativas no processo. 


\begin{tabular}{|c|c|c|c|c|c|c|}
\hline \multicolumn{3}{|c|}{ Período } & $\begin{array}{l}\text { GAP } \\
\text { Média }\end{array}$ & Produção & Potência & Produção / \\
\hline \multirow{3}{*}{ Mineral } & $\mathrm{N}$ & Valid & $33.125,00$ & $33.125,00$ & $33.125,00$ & $33.125,00$ \\
\hline & \multicolumn{2}{|c|}{ Erro Padrão } & 0,01 & 0,93 & 3,36 & 0,63 \\
\hline & \multicolumn{2}{|c|}{ Média } & 4,62 & 884 ton/hora & $1.410 \mathrm{~kW}$ & 196,92 \\
\hline \multirow{3}{*}{$\begin{array}{c}\text { KLUBERSYNTH } \\
\text { GH 6-320 }\end{array}$} & $\mathrm{N}$ & Valid & $33.069,00$ & $33.069,00$ & $33.069,00$ & $33.069,00$ \\
\hline & \multicolumn{2}{|c|}{ Erro Padrão } & 0,02 & 1,32 & 4,62 & 0,99 \\
\hline & \multicolumn{2}{|c|}{ Média } & 3,47 & 925 ton/hora & $1.395 \mathrm{~kW}$ & 259,12 \\
\hline & \multicolumn{2}{|c|}{ Diferença } & $-33,1 \%$ & $4,6 \%$ & $-1,1 \%$ & $24,0 \%$ \\
\hline
\end{tabular}

Tabela 2 - Comparação Estatística

A primeira observação é que houve uma pequena redução da potência elétrica no motor $(1,1 \%)$, devido ao fato de que a potência elétrica também é uma variável de processo do equipamento, sendo que o nível de produção é ajustado de acordo com a potência lida, colocando assim o equipamento em condição de produtividade máxima. Uma vez que a potência lida cai, o operador do processo aumenta a vazão de minério alimentado até a potência máxima de set point $(1.400 \mathrm{~kW})$, e por esta ótica detecta-se o ganho de maior produção de 4,6\%, gerando uma redução média no consumo específico ( $\mathrm{kWh} / \mathrm{ton}$ ) de $5,8 \%$. Este ganho por si já é um ganho bastante representativo, porém também foi observado que no período pós retrofit (óleo sintético Klüber Lubrication) o equipamento trabalhou numa condição de GAP menor, que é uma condição de maior esforço $\frac{V 2}{G A P}$, concluindo que por este meio a comparação é mais precisa.

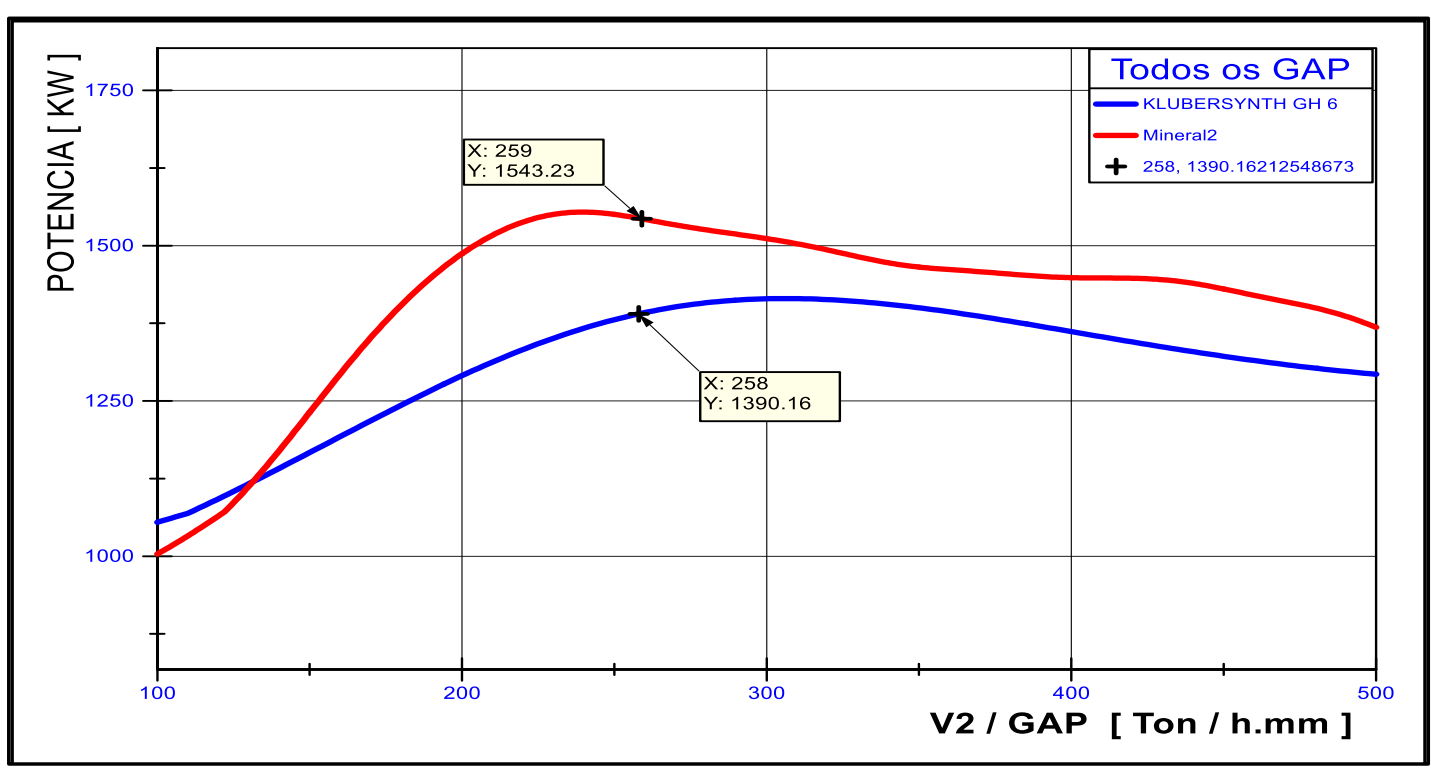

Figura 5- Comportamento da Potência de acordo com variação de $\frac{V 2}{G A P}$

Fazendo-se a comparação na mesma condição de $\frac{V 2}{G A P}=259$, que é a média observada no período com óleo sintético Klüber Lubrication, observa-se que a potência média caiu do valor de $1.543,23 \mathrm{~kW}$ para $1.390,16 \mathrm{~kW}$, gerando na mesma condição de trabalho a redução de potência de 153,1 kW, ou de 9,92 \% em vez de $5,8 \%$. 
Esta redução de potência, em termos financeiros, representa valores bastante relevantes para a empresa, visto que há outros equipamentos similares instalados nesta planta. Levando em consideração o preço médio de energia de $R \$$ 170,00/MWh aplicado na indústria de mineração, este benefício financeiro pode ser representado como abaixo:

\begin{tabular}{|c|c|}
\hline \multicolumn{2}{|c|}{ BENEFíCIOS FINANCEIROS } \\
\hline Produção Média Mensal & 917,7 ton / $\mathrm{h}$ \\
\hline Horas trabalhadas por Mês & 700 horas \\
\hline Volume Produzido no Mês & $642.374,8$ ton \\
\hline Redução do Consumo Específico & $0,167 \mathrm{KWh} /$ ton \\
\hline Economia de Energia no Mês & $107,191 \mathrm{MWh}$ \\
\hline Preço de Energia & $\mathrm{R} \$ 170 / \mathrm{MWh}$ \\
\hline Economias & $\mathrm{R} \$ 18.222,5 / \mathrm{Mes}$ \\
\cline { 2 - 2 }$\$ 218.669,6 /$ ano \\
\hline \multirow{2}{*}{ Investimento Adicional para a Troca de Óleo } & $\mathrm{R} \$ 49.000$ \\
\hline Pay Back Simples & 3 Meses \\
\hline
\end{tabular}

Tabela 3- Benefício Financeiro em Prensa de Rolos

Devido ao nível de refino que segue a teoria clássica da Mecânica Dinâmica, o resultado mais preciso e tecnicamente correto seria a aplicação do método Produção/ GAP tendo como resultado referência a redução no valor de 9,92 \% ou $0,167 \mathrm{KWh} /$ ton.

\section{TORRE DE RESFRIAMENTO}

Torres de resfriamento são equipamentos largamente empregados na siderurgia com a finalidade de resfriar a água quente do processo por meio de troca térmica com ar atmosférico. São equipamentos onde, devido à alta presença de umidade no ar, o ambiente é altamente agressivo para os equipamentos onde há elementos ferrosos. Neste equipamento, normalmente há um redutor de acionamento das hélices que ficam no topo, com a finalidade de aumentar a velocidade destas, e assim aumentar a eficiência de troca térmica. Muitas vezes, a manutenção de um redutor neste equipamento, como por exemplo a troca do lubrificante do redutor requer ações onerosas e até perigosas tais como aluguel de guindastes e trabalho em altura.
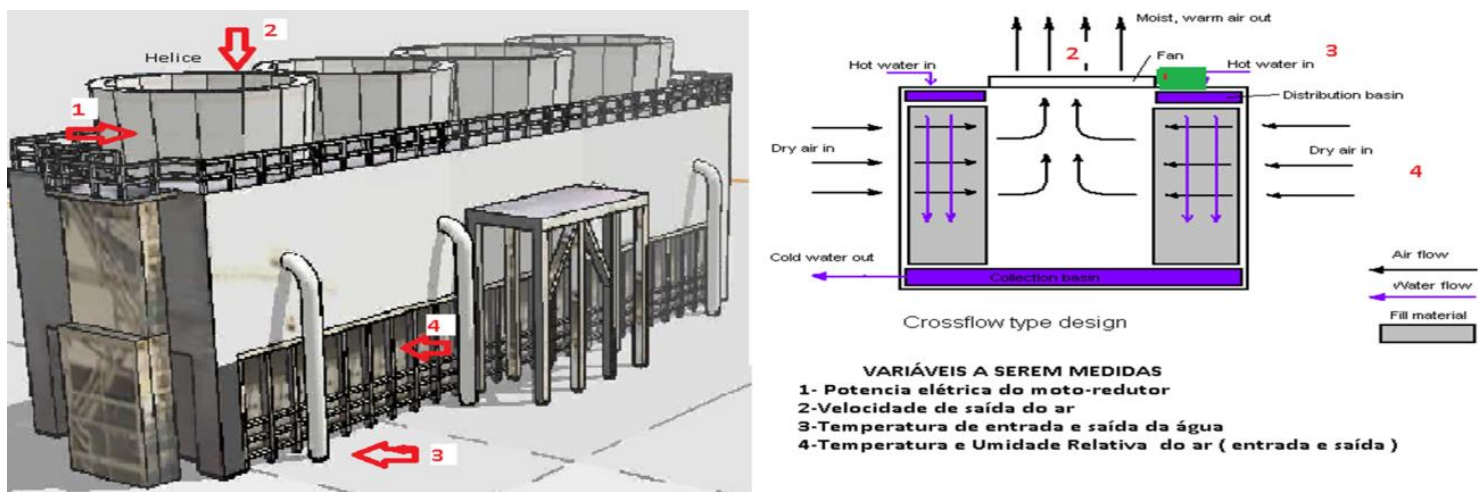

Figura 6-Torre de resfriamento - esboço do autor 1 
Analogamente ao modelo para prensa de rolos, nas torres de resfriamento as seguintes condições devem ser ajustadas para comparação:

- Mesma temperatura e umidade relativa;

- Mesma vazão de água (identificada pela pressão nas bombas);

- Mesma velocidade de ar;

- Período de medição na torre da utilidades:

O período de medição para as duas condições foi o seguinte:

- Baseline (Óleo mineral) - 5 dias (31/10/14 a 04/11/15)

- Pós-retrofit (Óleo sintético) - 5 dias (03/12/14 a 08/12/15)

Devido à estabilidade mecânica das hélices, os períodos de medição são relativamente curtos, desde que feitos em períodos próximos e climas muito semelhantes.

O rendimento da torre, para efeito de comparação, foi medido por meio da carga térmica, dada em função da variação de entalpia no processo e da vazão mássica de água.

- A comparação feita será do consumo de energia para uma mesma carga térmica;

- A carga térmica é função da vazão mássica e da entalpia:

\section{Carga Térmica $=\dot{\mathbf{m}} \mathbf{x} \Delta \mathbf{h}$}

hw1 $=$ entalpia de entrada do ar

$$
\Delta h=h w_{1}-h w_{2}
$$

hw2 = entalpia de saída do ar

$\mathrm{m}$ = vazão mássica do ar na saída da torre

A eficiência energética do processo é dada pela relação abaixo:

$$
\text { Relação de eficiência }=\frac{\text { Potência }[\text { kW] }}{\text { carga Térmica }}
$$

Quanto menor o fator acima, melhor a eficiência do processo e maior é a economia.

\subsection{Resultados}

Na torre de resfriamento foi analisado o comportamento da variação de potência em função da carga térmica:

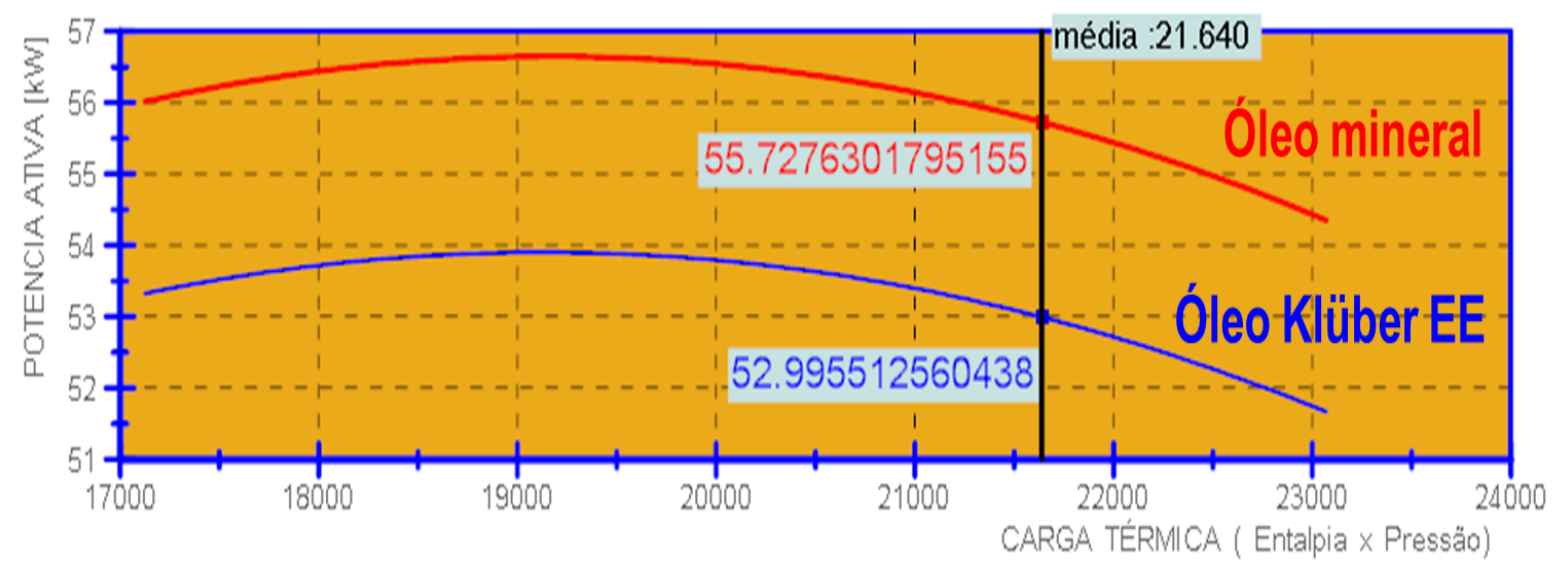

Figura 7- Avaliação conforme carga térmica 
Pode-se verificar claramente que há redução de potência elétrica no motor de acionamento do redutor trabalhando com óleo sintético Klüber Lubrication.

- No período pós retrofit a carga térmica média foi de 21.640. Este valor foi utilizado como referência para comparação.

- Diferença média: 2,73 kW

- Ganho médio: 4,87\%

\begin{tabular}{|lc|}
\hline \multicolumn{2}{|c|}{ Economia com energia em 1 redutor } \\
\hline Potencia Média de Operação & $56,00 \mathrm{KW}$ \\
Horas de Operação por Ano & $8.640 \mathrm{Hours}$ \\
Consumo Anual de Energia & $483.840 \mathrm{KWh}$ \\
\hline Redução Média de Potencia & $2,74 \mathrm{KW}$ \\
Economia de Energia & $23.639 \mathrm{KWh}$ \\
Preço de Energia ( $\mathrm{R} \$ / \mathrm{MWh}$ ) & $\mathrm{R} \$ 130,00$ \\
\hline Economia Anual & $\mathrm{R} \$ 3.073,08$ \\
\hline
\end{tabular}

Tabela 4 - Economia no redutor da torre de resfriamneto

O ganho financeiro para um equipamento não é tão expressivo quanto o encontrado para a prensa de rolos, porém considerando a quantidade de redutores em uma planta siderúrgica (diversos redutores por torre, e diversas torres em uma planta, dependendo do tamanho da planta) a migração para um lubrificante de melhor desempenho é justificada.

\begin{tabular}{|c|c|c|}
\hline \multicolumn{3}{|c|}{ Análise de custo-benefício para 1 redutor } \\
\hline \multirow{3}{*}{$\begin{array}{l}\text { Quantidade de redutores } \\
\text { Volume do reservatório }\end{array}$} & \multicolumn{2}{|r|}{1} \\
\hline & \multicolumn{2}{|r|}{60 Litros } \\
\hline & Óleo Mineral & KLUBERSYNTH GH $6-320$ \\
\hline Preço por Litro & $\mathrm{R} \$ 5,00$ & $\mathrm{R} \$ 50,00$ \\
\hline Investimento para troca de Óleo & $\mathrm{R} \$ 300,00$ & $\mathrm{R} \$ 3.000,00$ \\
\hline Período de troca & 1 ano & 4 anos \\
\hline Custo anual do óleo & $\mathrm{R} \$ \mathbf{3 0 0 , 0 0}$ & $\mathrm{R} \$ \mathbf{7 5 0 , 0 0}$ \\
\hline Economia de Energia & 0 & $\mathrm{R} \$ 3.073,08$ \\
\hline Despesa Total por Ano & $\mathbf{R} \$ \mathbf{3 0 0 , 0 0}$ & $-R \$ 2.323,08$ \\
\hline \multicolumn{3}{|c|}{ Atratividade de Investimento } \\
\hline Investimento para troca de Óleo & $\mathrm{R} \$ 3.000,00$ & \\
\hline Economia de energia anual & $\mathrm{R} \$ 3.073,08$ & \\
\hline Pay back & 1 ano & 12 meses \\
\hline
\end{tabular}

Tabela 5- Benefício financeiro torre de resfriamento

Com o período de troca 4 vezes maior, o investimento para troca do lubrificante seria pago no primeiro ano, evitando adicionalmente as despesas operacionais para a troca do óleo mineral como aluguel de guindastes e mão de obra.

\section{CONCLUSÃO}

O resultado obtido de aproximadamente $10 \%$ de redução de consumo específico de energia em prensa de rolos e de 4,9\% em torres de resfriamento representa um benefício financeiro que não deve ser ignorado pelas empresas que buscam 
aumento de eficiência energética em seus processos, e mostra que a prática de adotar lubrificante sintético de alta performance é uma alternativa prática e de rápido retorno financeiro dentre as soluções de eficiência energética atualmente disponíveis.

Este conceito pode ser aplicado com o mesmo benefício na indústria siderúrgica e de mineração, em qualquer redutor - com diferentes ordens de grandeza - que trabalhe com cargas próximas de sua capacidade nominal.

Há que se ressaltar que o ganho financeiro com benefício energético é uma opção da gestão da empresa, visto que em muitos casos o ganho de produtividade pode vir a ser o ganho financeiro mais relevante.

Além dos benefícios financeiros com a redução do consumo específico, há diversos outros benefícios operacionais e mecânicos provenientes da redução de atrito pela melhor lubrificação, que podem ser considerados no projeto:

Aumento da eficiência dos pares de engrenagens;

- Menor desgaste dos pares de engrenagem, ou seja, menos despesas com manutenção;

- Aumento da eficiência por melhor agitação do óleo;

- Redução da temperatura de operação;

- Aumento da vida útil do lubrificante de 1 ano com óleo mineral para até 5 anos;

- Maior estabilidade à oxidação; e

- Menor resíduos no reservatório. 